University of Nebraska - Lincoln

DigitalCommons@University of Nebraska - Lincoln

Faculty Publications from Nebraska Center for

Materials and Nanoscience, Nebraska Center Materials and Nanoscience

2008

Geometrical Interpretation and Simulation of HOLZ Patterns

Xingzhong Li

University of Nebraska - Lincoln, xli2@unl.edu

Follow this and additional works at: https://digitalcommons.unl.edu/cmrafacpub

Part of the Nanoscience and Nanotechnology Commons

Li, Xingzhong, "Geometrical Interpretation and Simulation of HOLZ Patterns" (2008). Faculty Publications from Nebraska Center for Materials and Nanoscience. 96.

https://digitalcommons.unl.edu/cmrafacpub/96

This Article is brought to you for free and open access by the Materials and Nanoscience, Nebraska Center for (NCMN) at DigitalCommons@University of Nebraska - Lincoln. It has been accepted for inclusion in Faculty Publications from Nebraska Center for Materials and Nanoscience by an authorized administrator of DigitalCommons@University of Nebraska - Lincoln. 


\title{
Geometrical Interpretation and Simulation of HOLZ Patterns
}

\author{
X.Z. Li
}

Nebraska Center for Materials and Nanoscience, University of Nebraska, Lincoln, NE 68588

Higher-order Laue zone (HOLZ) pattern is very useful in measurement of crystalline lattice parameters, strain and composition variation in a small area of sample [1,2]. Bloch dynamical theory on convergent-beam electron diffraction (CBED), including the formation of HOLZ lines, has been well developed and documented in Ref. [1] and references therein. Although CBED patterns and included HOLZ lines are best modeled using a dynamical formulation, models based on a geometrical interpretation for the HOLZ-line positions have remained in widespread use because of their simplicity. Moreover, the geometrical interpretation is helpful to understand the formation of HOLZ lines for beginners. The geometrical interpretation of HOLZ lines can be carried out in either Ewald sphere construction or dispersion surface construction [3].

As shown in Ref. [1], a general formula for HOLZ lines in the kinematic approximation is directly derived from the Bragg law. The same formula of the HOLZ lines can also be derived using the geometrical relation in the Ewald sphere construction. Following the Fig. 3 in Ref. [3], the HOLZ line can be described as,

$$
g_{x} k_{x}+g_{y} k_{y}-g_{z} k_{z}+\frac{g^{2}}{2}=0
$$

Here $\mathbf{g}=\left(\mathrm{g}_{\mathrm{x}}, \mathrm{g}_{\mathrm{y}}, \mathrm{g}_{\mathrm{z}}\right)$ and $\mathbf{k}=\left(\mathrm{k}_{\mathrm{x}}, \mathrm{k}_{\mathrm{y}}, \mathrm{k}_{\mathrm{z}}\right)$ are reciprocal vector and incident electron beam, respectively.

The dispersion surface construction is an alternative way to formulate the geometrical interpretation of the formation of HOLZ lines. Furthermore, it is especially useful for incorporating the description of some dynamical effects on HOLZ lines, e.g. shift and curvature of HOLZ lines. Fig. 1 shows schematic diagrams of the formation of HOLZ lines using the dispersion surface construction in two different cases, the first branch of the dispersion surface can be approximately considered as a sphere with its origin at $\mathrm{O}$ and radii of $\mathrm{k}_{1}=\mathrm{k}_{0}+\gamma^{(1)}$ in (a) and a flat plane in (b). The HOLZ line in Fig. 1 (a) is described as a line defined in (2) and in Fig.1 (b) a section of a circle, for details see [3].

$$
g_{x} k_{x}+g_{y} k_{y}-g_{z} k_{z}+\frac{g^{2}}{2}+g \Delta g=0
$$

Here $g \Delta g=\left(k \gamma^{(1)}+\frac{\left(\gamma^{(1)}\right)^{2}}{2}\right)$. The equation is deviated from the result of the dynamical theory [1] by a rather small quantity of $\left(\gamma^{(1)}\right)^{2} / 2$ considering $k>>\gamma^{(1)} / 2$.

An interactive computer program for simulation of the HOLZ line patterns, JECP/HOLZ, has been developed [4]. A feature of this program is the integration of the simulation of the HOLZ reflections and the HOLZ (curved and straight) lines, which is interactive with respect to changes of the lattice parameter, the accelerator voltage, the zone axis, and the beam tilt. Figure 2 shows GUI of the JECP/HOLZ with (a) simulated and (b) experimental HOLZ patterns of Si [553]. The program in compressed form (jecp_holz.zip), including a specification file, is available at http://www.unl.edu/CMRAcfem/XZLI/programs.htm. The program runs in demo mode without registration code, which can be requested from author. 


\section{References}

[1] J.C.H. Spence and J.M. Zuo, Electron microdiffraction, Plenum Press, 1992.

[2] M. De Graef, Introduction to Conventional Transmission Electron Microscopy, Cambridge University Press, 2003.

[3] X.Z. Li, J. Mater. Educ. 29 (2007) 177.

[4] X.Z. Li, J. Appl. Cryst. 38 (2005) 576.
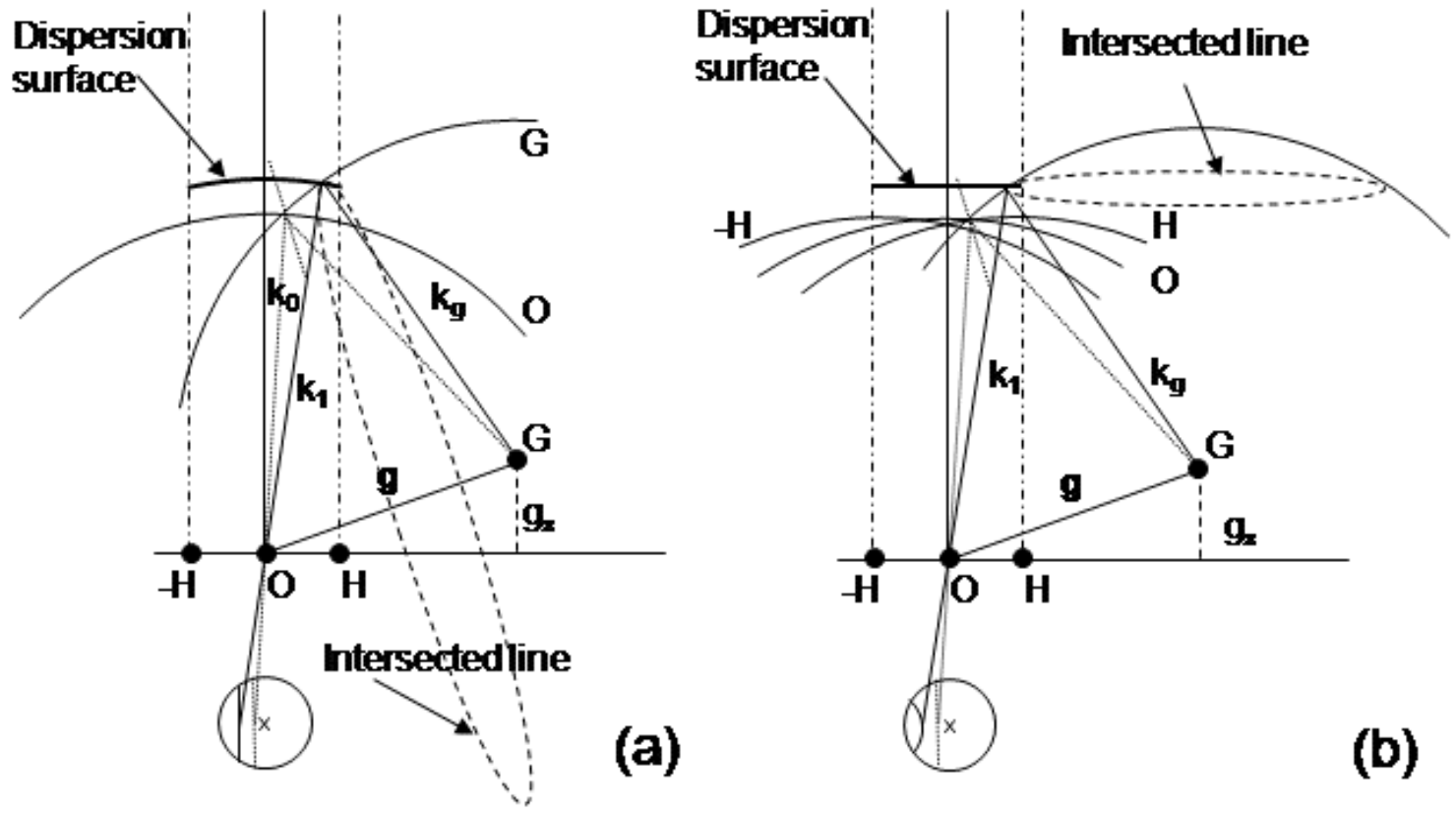

Fig.1. Schematic diagrams of the formation of HOLZ lines using the dispersion surface construction: (a) weak dynamical effect and (b) strong dynamical effect in a zero order Laue zone. The intersected lines are valid within the first Brillouin zones and the extensions of the intersected lines to form circles are for illustration purposes only.

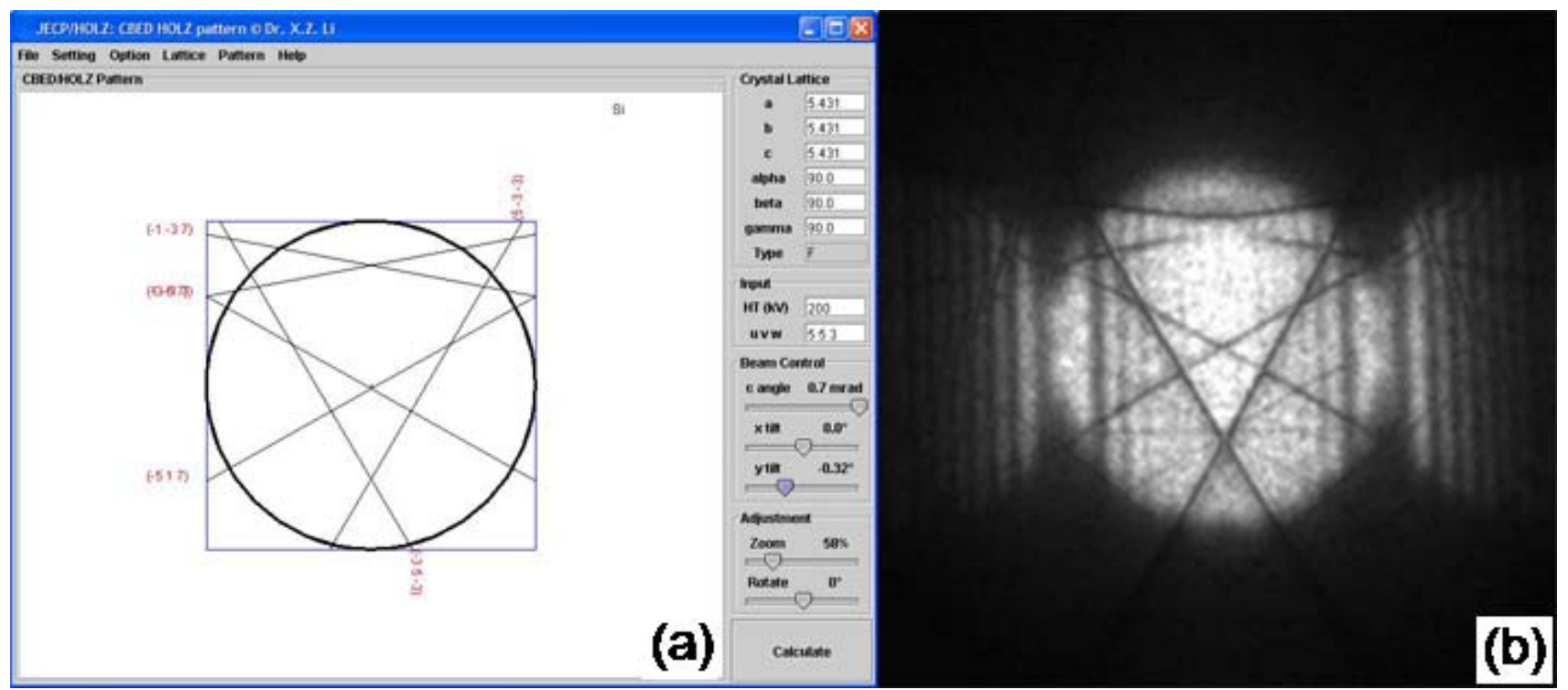

Fig. 2 GUI of JECP/HOLZ with (a) a simulated and (b) an experimental HOLZ patterns of Si [553]. 